Citation: Bennett, C. Stewart, R.A. and Beal, C.D. (2012) ANN-Based residential water end-use demand forecasting model. Expert Systems with Application, Volume 40, Issue 4, 1014-1023.

\title{
ANN-Based Residential Water End-use Demand Forecasting Model
}

\section{Christopher Bennett}

Research Associate, Smart Water Research Centre, Griffith University, Gold Coast Campus 4222, Australia, Email: christopher.bennett2@griffithuni.edu.au

\section{Rodney A. Stewart}

Director, Centre for Infrastructure Engineering and Management, Griffith University, Gold Coast Campus 4222, Australia, Email: r.stewart@griffith.edu.au

\section{Cara D. Beal}

Research Fellow, Smart Water Research Centre, Griffith University, Gold Coast Campus 4222, Australia, Email: c.beal@griffith.edu.au 


\title{
ANN-Based Residential Water End-use Demand Forecasting Model
}

\begin{abstract}
Bottom-up urban water demand forecasting based on empirical data for individual water end uses or micro-components (e.g., toilet, shower, etc.) for different households of varying characteristics is undoubtedly superior to top-down estimates originating from bulk water metres that are currently performed. Residential water end-use studies partially enabled by modern smart metering technologies such as those used in the South East Queensland Residential End Use Study (SEQREUS) provide the opportunity to align disaggregated water end-use demand for households with an extensive database covering household demographic, socio-economic and water appliance stock efficiency information. Artificial Neural Networks (ANNs) provide the ideal technique for aligning these databases to extract the key determinants for each water end-use category, with the view to building a residential water end-use demand forecasting model. Three conventional ANNs were used: two feed-forward back propagation networks and one radial basis function network. A sigmoid activation hidden layer and linear activation output layer produced the most accurate forecasting models. The end-use forecasting models had $R^{2}$ values of $0.33,0.37,0.60,0.57,0.57$, 0.21 and 0.41 for toilet, tap, shower, clothes washer, dishwasher, bath and total internal demand, respectively. All of the forecasting models except the bath demand were able to reproduce the means and medians of the frequency distributions of the training and validation sets. This study concludes with an application of the developed forecasting model for predicting the water savings derived from a citywide implementation of a residential water appliance retrofit program (i.e., retrofitting with efficient toilets, clothes washers and shower heads).
\end{abstract}

Keywords: Artificial neural network, residential water demand forecasting, water end use, water micro-component, water demand management 


\section{Introduction}

The urbanised South East Queensland (SEQ) region in Australia, like many other inhabited regions, faces a series of complex problems involving the supply and demand management of water resources. From 2005 to 2008, SEQ endured a severe drought in conjunction with high population growth (Queensland Water Commission, 2009). In response, water demand management programs and policies were instituted to reduce demand and prolong the duration of an adequate supply of water. However, given that there was inadequate understanding of the relationship between end-use water demand (e.g., for showers) and household characteristics, the effectiveness of the water demand management schemes (e.g., a shower head replacement program) was difficult to determine with any degree of precision (Queensland Water Commission, 2009). In response to this limited understanding of residential water end-use demand, the South East Queensland Residential End Use Study (SEQREUS) was funded by the Queensland State Government (see Beal et al., 2011). The SEQREUS resulted in a large database containing aligned water end-use data for over 250 households, water appliance stock efficiency data, demographic data and socio-economic data. Artificial Neural Networks (ANNs) was deemed the most suitable technique to exploit this database to develop a residential water end-use demand forecasting model for the primary purpose of determining the effectiveness of a range of water demand management programs (e.g., household appliance stock retrofit programs).

\section{Background}

\subsection{Residential water end-use studies}

Residential water end-use studies utilise high-resolution smart water metering, data logging, flow trace analysis and surveys to determine the volume and features of each water end use, such as tap water use, clothes washer, dishwasher, shower, toilet, bath, irrigation and miscellaneous. These studies result in a comprehensive registry of disaggregated water consumption end uses (Loh \& 
Coghlan, 2003; Willis et al., 2009; Beal et al., 2010; Beal et al., 2011c; Gato et al., 2011; Willis et al., 2011). Information gathered from end-use studies and associated stock efficiency, sociodemographic and intervention studies allows greater understanding of the predictors of end-use water demand (Mayer et al., 1999; Loh \& Coghlan, 2003; Heinrich, 2009; Willis et al., 2010; Gato et al., 2011; Beal et al., 2011b; Makki et al., 2011; Willis et al., 2011). Such detailed stochastic information can inform enhanced urban water demand practices and policy. The end-use study dataset underpinning this empirical modelling study is described briefly in the next section.

\subsection{SEQREUS}

The SEQREUS was a \$1M research project funded by the Urban Water Research Security Alliance (UWRSA) from 2009-2011 and completed by the Smart Water Research Centre (SWRC) located at Griffith University. The objectives of the greater SEQREUS were to calculate household and per capita disaggregated consumption, reveal key determinants of water end-use demand, study diurnal demand patterns at an end-use level and assess the influence of water-efficient appliances (Beal et al, 2011c). This particular sub-study utilises an end-use dataset collected in June 2010 covering 252 detached households in four interconnected cities (i.e., Brisbane, Gold Coast, Ipswich and Sunshine Coast) located in the greater SEQ region. Moreover, this sub-study employs a comprehensive aligned dataset consisting of appliance stock efficiency, demographic and socio-economic variables for each of these households. These aligned datasets provided the foundations of the ANN-based residential water end-use demand forecasting model discussed here and associated water efficiency retrofit program simulation. The model focused on the internal demand end uses, which were consistent over the study period. The irrigation or outdoor end-use category was not included in this forecasting model because this end-use category is highly variable from day to day and requires end-use data over numerous seasonal periods over many years to provide a satisfactory dataset. However, the omission of the outdoor end-use category is not considered a limitation of this present study, as the key goal was to model scenarios of water stock efficiency and demographic parameters 
for different households, thereby informing best-practice water efficiency programs.

\subsection{Reported predictors of water end-use demand}

The predominant variables influencing total and disaggregated water demand include socioeconomic and demographic variables, regional and climatic variables and appliance stock efficiency (Beal et al., 2010; Beal et al., 2011b). This purpose of this section is to outline the reported variables affecting total and disaggregated water demand.

Socio-economic and demographic variables include household size, number of adults, number of children, number of teenagers, gender, age, income and education. Socio-economic and demographic variables are not generally independent and can thus be correlated with one another (Neter et al., 1983). Highly correlated socio-economic and demographic variables can therefore be used as proxy variables (Arbues et al., 2003). The typical practice when developing linear regression models is to include interaction terms between interrelated variables to reduce overexplanation of the system and error terms (Neter et al., 1983).

Household size or occupancy has a highly significant causal relationship to both per household demand and per capita demand. As expected, as occupancy of a household increases, so does its demand for water. However, an increase in water demand with an increasing number of household occupants is by no means a linear relationship (Heinrich, 2009; Beal et al., 2011a; Gato, 2011; Lee et al., 2012). Conversely, when analysing per capita demand against household occupancy, household per capita consumption decreases as household size increases (Beal et al., 2010; Gato, 2011). The decrease in per capita consumption with increasing consumption relates to an 'economyof-scale' effect within the household (Beal et al., 2011a). Additionally, reduced per capita consumption could be related to greater competition for water using devices in peak periods, thereby reducing each occupant's usage (i.e., reduced time in the shower during the morning rush). 
Considering the age characteristics of household occupants provides a better estimate of end use consumption (Makki et al., 2011). On average, households with younger children are lower water consumers than households containing predominantly teenagers, especially for shower use. Arbues et al. (2003) describes an optimum household size as well as the point where the economies of scale vanish, based on a correlation between the age gap between offspring and, hence, a greater possibility of more teenagers occurring in a larger household.

Beal et al. (2011a) observed that older households, based on average occupant age, used more water per capita than younger households. Willis et al. (2009) hypothesised that retired individuals spend a relatively greater proportion of their time at home and thus have a greater opportunity to use water-dependent appliances. Similarly, Kenney et al. (2008) observed that as the mean age of a household increases, so does household water consumption. Kenney et al. (2008) also outlined the correlation between age, household income and wealth, noting that the increase of water consumption per household is a result of the combination of these variables.

Household income has been reported to have a variety of relationships with water consumption. Loh \& Coghlan (2003) found that households with greater incomes have greater per capita and household water consumption than households with lower incomes, due mainly to much higher discretionary irrigation end-use demand. Beal et al. (2011a) outlined a trend of larger, high-income households using less water per capita than smaller, low-income households. Kenney et al. (2008) also observed that higher income households consume more water on a household basis than lower income households. The conflicting results highlight the importance of reporting water demand in water end-use categories (e.g., shower use) and on a per capita basis. Such reporting provides a levelised comparison.

Water-use stock and appliance efficiency, commonly measured by water efficiency labelling schemes (e.g., WELS in Australia and WaterSense in the United States), is the unit amount of water used or consumed per unit of time (e.g., min) for a particular water end use device. Higher 
efficiency ratings (e.g., 5 stars) have lower water consumption (i.e., 6 L/min). Beal et al. (2011a) analysed the efficiency of clothes washers and shower heads against daily per capita water consumption. Clothes washers rated 3 stars or less had an average of $35.1 \mathrm{~L} / \mathrm{p} / \mathrm{d}$ consumption, whereas clothes washers having 4 stars or less had an average consumption of $28.3 \mathrm{~L} / \mathrm{p} / \mathrm{d}$. This difference equates to a saving of $6.6 \mathrm{~L} / \mathrm{p} / \mathrm{d}$ (Beal et al., 2011a). Similar stock efficiency comparisons for shower heads showed a significant 13.9 L/p/d saving (Beal et al., 2011a). Other studies have reinforced this finding, showing that water efficient appliances result in decreased water demand (Gato, 2006; Kenney, 2008, Heinrich, 2009).

\subsection{Residential water end use demand modelling}

The modelling of residential water end-use demand requires the application of analytical techniques (e.g., Bayesian networks, multi-variable regression and stochastic modelling) and an extensive database of predictor variables. While a number of studies have presented models that are capable of predicting total residential demand (Froukh, 2001; Jorgensen et al., 2009; Polebitski \& Palmer, 2010), far fewer studies have attempted to predict water end-use demand. The advent of highresolution smart metering and water end-use disaggregation software tools have allowed end-use modelling to be performed with a reasonable degree of accuracy.

Gato (2006) employed a multi-variable regression approach, applying empirical information collected from the Melbourne Residential End Use Study. Various tailored demographic variables were used to predict the demand of particular water end uses. Predictor variables identified from regression modelling included the number of adults, the number of children less than 12 years of age, the number of children 12 and older, and appliance information, such as ownership of a dishwasher, the type of clothes washer and the fraction of dual flush toilets in the household. Significant prediction models were produced for the following water end uses: total internal demand; toilet demand; shower demand; clothes washer demand; dishwasher demand; and tap 
demand.

Blokker et al. (2010) developed a stochastic end-use model based on demographics, end-use category frequency of use, flow duration and event occurrence likelihood to simulate water demand patterns. To develop this stochastic end-use model, a Poisson rectangular pulse model was derived from smart water metering studies and surveys (Blokker et al., 2010). The final stochastic end-use model approach developed by Blokker et al. (2010) accounted for 0.93 of the observed variance for the diurnal pattern of water demand.

Hsiao et al. (1995) adapted a Bayesian conditional demand framework to develop a forecasting model to predict electric water heating associated with residential water demand end uses. The construction of the Bayesian models involved the formation of appliance dummy variables and transforming the variables into fractions of demographics and weather variables (Hsiao et al., 1995). The variables were then combined with aggregated loads, appliance ownership and demographic information. The method was applied to two data sets containing 49 and 347 homes, respectively, and produced models with acceptable relative errors ranging from 0.081 to 0.298.

There have been some recent attempts to predict residential water end-use demand. While these techniques appeared satisfactory by meeting certain statistical significance or reliability thresholds, each technique had particular advantages and weaknesses. The multi-variable regression modelling approach applied by Gato (2006) benefits from being less complex than the other methods but is susceptible to over-predicting the system due to multi-collinearity of independent variables (Hsiao et al. 1995). The stochastic modelling approach benefits by its universal applicability because it is not reliant on direct measurements (Blokker et al., 2010). The Bayesian conditional demand framework using a small sample of metered houses and aggregated load information can produce accurate models (Hsiao et al., 1995).

Modelling residential water end-use demand invariably is a process mired in the highly variable 
preferences of consumers and intercorrelated nonlinear demographic information. High-income category households, as compared to other income categories, are observed to have a higher frequency of children in the household. The reasoning behind this observation is that, as people age, they move into higher income brackets corresponding to their experience in the work force, and with age they are more likely to get married and have children. ANN modelling techniques have an ability to adapt, learn and generalise relationships occurring within input information (Karayiannis \& Venetsanopoulos, 1993). To improve on the modelling of residential water demand end uses, due to the properties of the ability to adapt, learn and generalise, ANN modelling techniques are predicted to be better suited to dealing with highly variable data sets and intercorrelated nonlinear inputs.

\section{Artificial neural networks}

\subsection{Overview}

ANNs are comprised of one or more processing units called 'artificial neurons' or 'perceptrons' (Karayiannis and Venetsanopoulos, 1993). Perceptrons of an ANN are interconnected with one another by a series of weighted connections. The perceptrons of an ANN, depending on the system being replicated, are arranged in layers, with each perceptron of the preceding layer having a weighted connection with each neuron of the proceeding layer. In the process of ANN training to replicate a system, a training data set is fed through the network. Each perceptron processes the input data or input signal from either the input layer or the preceding perceptrons. The final layer of the ANN produces an output signal. The weights and structure of the network are altered in a manner depending on the specific training algorithm.

\subsection{Perceptron}

The perceptron is comprised of several components including the weights of the inputs, the 
summation function, the activation function and the output (Karayiannis and Venetsanopoulos, 1993). The weights of the inputs act as a linear multiplier to change the magnitude of the input value. There is an input weight connected to the neuron for each input variable. The summation function acts to sum all weighted input signals. The summation term is then inputted into the activation function to produce an output. The activation function of the perceptron is dependent on the type of ANN and the desired application.

\subsection{ANN structure}

The structure of an ANN falls into one of two main categories: single-layer networks and multiplelayer networks. Single-layer networks comprise an input layer of values and an output layer of perceptrons. Multi-layered networks consist of an input layer of values, one or more hidden layers of perceptrons and an output layer of perceptrons. The number of perceptrons in each layer is dependent on the nature of the model being predicted.

\subsubsection{Linear Activation Perceptron}

Eqs. 1 to 3, below, display the function of the linear activation perceptron.

$$
\begin{aligned}
& v_{j}=\sum_{h=1}^{m} w_{j h} x_{h} \\
& \sigma\left(v_{j}\right)=v_{j} \\
& Y_{j}=\sigma\left(v_{j}\right)
\end{aligned}
$$

where $x$ is the input vector of input variables, $x_{h}$ is the input variable $h$ of the input vector, $m$ is the number of input variables, $w_{j h}$ is the weighted connection from input variable $h$ to perceptron $\mathrm{j}, v j$ is the summation term of perceptron $j, \sigma$ is the perceptron activation function, and $Y_{j}$ is the output from perceptron $j$. 


\subsubsection{Sigmoid activation perceptron}

Eqs. 4 to 6, below, display the function of the sigmoid activation perceptron,

$$
\begin{aligned}
& v_{j}=\sum_{h=1}^{m} w_{j h} x_{h} \\
& \sigma\left(v_{j}\right)=\frac{6}{1+e^{-\alpha v_{j}}}-3 \\
& Y_{j}=\sigma\left(v_{j}\right)
\end{aligned}
$$

where the variables are defined as above.

\subsubsection{Radial basis function perceptron}

Eq. 7, below, displays the function of the radial basis function perceptron.

$$
Y_{j}(x)=\sqrt{1+\frac{h}{d^{2}}\left\|x-c_{j}\right\|}
$$

where $x$ is the input vector of input variables, $c_{j}$ is the radial basis centre of perceptron $j, h$ is the number of hidden perceptrons, $d$ is the greatest Euclidean distance between radial basis centres, and $Y_{j}$ is the output from perceptron $j$.

\subsubsection{Error back propagation}

The weights connecting the hidden layer to the output layer are updated according to error back propagation by eq. 8 below.

$$
w_{k i}(t+1)=w_{k i}(t)+\alpha\left(Y_{j k}-Y_{k}\right) \sigma^{\prime}\left(v_{k}\right) Y_{i}
$$

where $Y_{i}$ is the output from perceptron i of the hidden layer, $Y_{j k}$ is the output from perceptron $k$ of the output layer, $Y_{k}$ is the observed value of perceptron $\mathrm{k}, v_{k}$ is the summation term of perceptron $k$, $\alpha$ is the training rate, $w_{k i}$ is the weighted connection from the output of the hidden perceptron $i$ to 
perceptron $k, w_{k i}(t)$ is the weight of the current epoch, and $w_{k i}(t+1)$ is the weight of the next epoch.

The weights connecting hidden layers are updated according to error back propagation by eq. 9, below.

$$
w_{i h}(t+1)=w_{i h}(t)+\alpha\left(\sum_{k=1}^{m}\left(Y_{j k}-Y_{k}\right) \sigma^{\prime}\left(v_{k}\right) w_{k i}\right) \sigma^{\prime}\left(v_{i}\right) x_{h}
$$

where $Y_{i}$ is the output from perceptron i of the hidden layer, $Y_{j k}$ is the output from perceptron $k$ of the output layer, $Y_{k}$ is the observed value of perceptron $\mathrm{k}, v_{k}$ is the summation term of perceptron $k$, $\alpha$ is the training rate, $w_{k i}$ is the weighted connection from the output of the hidden perceptron $i$ to perceptron $k, x$ is the input vector of variables, $x_{h}$ is the input variable $h, m$ is the number of output perceptrons, $v_{i}$ is the summation term of perceptron $i, w_{i h}$ is the weighted connection from the input variable $x_{h}$ to perceptron $i, w_{i h}(t)$ is the weighted connection of current epoch, and $w_{i h}(t+1)$ is the weighted connection of the next epoch.

\subsubsection{Hybrid training method}

The radial basis centre is selected according to the minimum Euclidean distance between the input vector and the radial basis centres.

$$
c_{\min }=\min \left(\left\|x-c_{i}\right\|_{i=1}^{n}\right)
$$

where $x$ is the input vector, $c_{i}$ is the radial basis centre of perceptron $I, n$ is the number of radial basis perceptrons, and $c_{\min }$ is the radial basis centre pertaining to the minimum Euclidean distance.

The accuracy of the RBFN is calculated using the RMSE function. If the minimum Euclidean distance between the input vector and the radial basis centres is above a specified threshold $v$ and the RBFN accuracy acc is less than the desired level, the associated radial basis centre is shifted towards the input vector: 


$$
c_{\min }(t+1)=\left\{\begin{array}{lr}
c_{\min }(t)+\alpha\left[x-c_{\min }\right], \text { if }\left(\left\|x-c_{\min }\right\| \geq v \wedge\right. & R M S E \geq \text { acc } \\
c_{\min }(t), & \text { otherwise }
\end{array}\right\}
$$

where $x$ is the input vector, $c_{i}$ is the radial basis centre of perceptron $I, n$ is the number of radial basis perceptrons, and $c_{\min }$ is the radial basis centre pertaining to the minimum Euclidean distance, $v$ is the threshold, acc is the level of accuracy in terms of RMSE, $\alpha$ is the training rate, $c_{\min }(t)$ is the radial basis centre of the current epoch, and $c_{\min }(t+1)$ is the radial basis centre of the next epoch.

The weights connecting the radial basis function perceptrons to the output layer are calculated by error back propagation.

\subsection{Hidden layer sigmoid activation}

The Hidden Layer Sigmoid Activation (HLSA) Network consists of one input layer, a hidden layer of sigmoid activation perceptrons and an output layer of sigmoid activation perceptrons. The sigmoid activation function of the HLSA has been modified so that the output of the function can incorporate normalised values from -3 to +3 to allow the network to process transformed data. The HLSA is trained according to Error Back Propagation.

\subsection{Hidden layer sigmoid activation linearly activated output}

The Hidden Layer Sigmoid Activation Linearly Activation Output (HLSALAO) network is a hybrid network consisting of an input layer, a hidden layer of sigmoid activation perceptrons and an output layer of linearly activation perceptrons. The sigmoid activation function of the HLSALAO has been modified so that the output of the function can incorporate normalised values from -3 to +3 to allow the network to process transformed data. The HLSALAO is trained according to Error Back Propagation. 


\subsection{Radial basis function network}

The Radial Basis Function Network (RBFN) is structured according to an input layer, a hidden layer comprised of radial basis function perceptrons and an output layer consisting of linearly activated neurons. The radial basis centres of the radial basis function perceptrons are selected from the sample training set at random. The RBFN is trained according to the hybrid training method.

\section{Research objectives}

The objectives of this research investigation were the following:

1. Explore the feasibility of applying ANNs to the problem of residential water end use demand forecasting;

2. Develop an ANN-based residential water end use demand forecasting model; and

3. Apply the developed ANN-based model to simulate the potential savings derived from a water demand reduction retrofit program (e.g., retrofitting low efficiency shower heads and clothes washers with others of higher efficiency).

\section{Method}

\subsection{Overview}

To achieve the stated research objectives, the following key research stages were followed:

1. Identification of key determinants influencing residential end use demand.

2. Normalisation of the training and validation dataset provided.

3. Training of ANNs to produce disaggregated residential water demand end use models.

4. Statistical analysis of ANN-produced results related to both the training and validation sets to ensure that they meet accuracy statistical significance criteria. 
5. Development of an interactive water end use demand forecasting tool that can be used for a number of purposes, including examining the potential savings achievable from water appliance/fixture retrofit programs.

\subsection{Information and ANN input}

The SEQREUS provided a usable sample of 205 households that contained the entire dataset (i.e., water end-use data, water stock efficiency data, and demographic data for each household). For the analysis, a training set containing 175 samples was randomly selected, with the remaining 30 samples used for model validation

The numerous socio-economic, demographic and appliance efficiency variables within the dataset were selected as independent variables. These variables were the following: region; income; education level; occupancy; number of adults; number of children; number of teenagers; star rating of fixtures/appliances (i.e., tap, shower, clothes washer); and the installation of a dishwasher. The end use (e.g., shower) mean daily per household water consumption (i.e., L/hh/d) determined from the end use analysis process was set as the dependent variable.

For the purpose of identifying the significant determinants and subsequent inputs into the ANN models, the participant data collected by the SEQREUS was organised in ordinal categories. Table 1 details the established ordinal categories for the independent variables (i.e., socio-economic and demographic information).

\section{[INSERT TABLE 1]}

The efficiency of the water stock fixtures and appliances has been recorded and categorised in an ordinal manner according to the Water Efficiency Labelling Scheme (WELS) (AS/NZS 6400:2005). 
Table 2 displays the WELS categories for the various water use appliances such as taps, showers, clothes washers, dishwashers and toilets.

\section{[INSERT TABLE 2]}

\subsection{Models}

Model development was limited to predicting the homogeneous internal demand component of total residential demand. Outdoor irrigation demand was not included in the forecasting model. While these end-use data (i.e., irrigation end-use consumption) was available for three seasonal periods, this amount of data was not considered sufficient for a predictive model due to the highly variable nature of this end use (i.e., irrigation volumes change from day to day depending largely on environmental conditions such as temperature, humidity and rainfall). Additionally, household leakage was not considered in this internal demand model as this end use is also highly inconsistent, and its prediction is related to a range of other predictor variables not collected in this particular study (i.e., age of home, pipe material, toilet type, etc.).

In summary, the ANN methodology and the refined dataset of independent variables were used to develop a forecasting model to predict the consumption values of each of the following dependent variables (i.e., end-use categories and total indoor) on a litre per household per day (L/hh/d) basis: toilet demand; clothes washer demand; shower demand; dishwasher demand; tap demand; and total internal demand.

\section{Identifying key determinants}

The demographic and stock efficiency variables did not fulfil the requirements of normality of distribution and homogeneity of variances. Therefore, to identify key determinants that can be 
attributed to the effects of residential end uses, non-parametric tests such as the Kruskal-Wallis (KW) test and the Mann-Whitney Wilcoxon (MW) rank sum test were used to determine difference in distributions. A confidence interval of $90 \%$ was used to determine statistical significance. Linear regression analysis was applied to observe the statistical power of continuous variables to predict and account for the variance of residential water demand end uses. Table 3 below displays the independent variables, the mean values of the variables organised into ordinal categories, the statistical tests performed, the associated chi-square p-values and the linear regression analysis.

\section{[INSERT TABLE 3]}

The predominant key determinants affecting residential water demand end uses include household income, occupancy, the occurrence of children and the occurrence of teenagers. According to the WELS system, appliance stock efficiency was statistically significant only pertaining to toilet demand. Shower stock efficiency was found to be statistically significant when re-clustering star ratings into below two and above and equal to two. The identification of key determinants has revealed that each independent variable has at least one relationship of statistical significance with residential water demand end uses. Table 4 displays the input variables used to develop the disaggregated residential water demand end use models.

[INSERT TABLE 4] 


\section{Results and discussion}

\subsection{Examined ANN algorithms}

Table 5 displays the absolute relative error (ARE), average absolute error (AAE), root mean squared error (RMSE), Mann-Whitney Wilcoxon (MW) P-value and coefficient of determination $\left(R^{2}\right)$ for each residential water end use demand forecasting model produced corresponding to the applied ANN algorithms. The ANN algorithms resulted in a number of residential water end use demand forecasting models with varying degrees of accuracy. The HLSALOA model had the highest $R^{2}$ and the least error. This model will be discussed further below.

\section{[INSERT TABLE 5]}

\subsection{HLSALOA residential water demand end use forecasting models}

\subsubsection{Analysis of error and variance}

Table 6 displays the different residential water end-use demand values, ARE, AAE, RMSE, RMSE as $\%$ of mean and $R^{2}$ for the training set applied to the HLSALOA. The forecasting models produced by the HLSALOA varied in their ability to accurately predict demand. The forecasting model which had the least relative error was toilet demand and total internal demand, while dishwasher and bath demand forecasting models had the greatest error.

[INSERT TABLE 6] 
The forecasting models relating to toilet, tap, shower, clothes washer, dishwasher and total internal demand are statistically reliable because the RMSE is less than the observed means. Conversely, the bath demand forecasting model is not considered reliable because the RMSE value is greater than the observed mean. The $R^{2}$ values for the end use demand forecasting models ranged from 0.21 for bath demand to 0.6 for shower demand. Given that most end use demand models explained 50\% or greater of the observed variance, the demand forecasting models are deemed moderately reliable.

Table 7 below displays the statistical analysis results when applying the validation data set to the forecasting models produced by the HLSALOA. Findings presented similar error levels to those of the training set. For the validation data set assessment, toilet, tap, shower, dishwasher and total internal demand forecasting models had prediction errors less than the observed means, indicating that they are reliable for predicting end-use demand levels in a household.

\section{[INSERT TABLE 7]}

The ability of the developed tap, toilet, shower and dishwasher demand forecasting models to explain variability of the validation set was actually better than for the training set. The increased accuracy was likely a product of the random sampling to compile the set. The validation set has demand values closer to the predicted values of the models and or the expected values of the training set. With similarity to the training set, the clothes washer, bath and total internal demand forecasting models accounted for a level of variance similar to the training set. Prediction accuracy remaining robust for the validation testing analysis stage provides confidence that the input variables used to construct the forecasting models are reliable. 


\subsubsection{Analysis of prediction accuracy}

The purpose of the following analysis is to determine whether the forecasting models can reproduce the residential water demand end use frequency distributions. If the forecasting models can reproduce the means and the medians of the distributions, the forecasting models are applicable on a macro or region-wide level. In turn, the forecasting models can be used for purposes such as simulating appliance retrofit programs.

Figure 1 displays the mean of the observed and predicted standard mean and the t-test p-value for the training set and validation set of each end use forecast model produced by the HLSALOA. The t-test derived $p$-values range from 0.85 for dishwasher demand to 0.96 for total internal demand for the training set. The $t$-test derived $p$-values range from 0.74 for dishwasher demand to 0.97 for toilet demand for the validation set. In all cases, the residential water demand end-use models produced distributions according to the training and validation sets that did not deviate from the observed water demand distributions to a statistically significant level, providing evidence that the models produced can accurately forecast the distributions of residential end-use demands for a set of households.

\section{[INSERT FIGURE 1]}

A similar analysis was performed for the analysis of the replication medians for the training and validation sets under the Mann-Whitney Wilcoxon rank sum test. Apart from bath residential water demand end use, predicted demand distributions reproduced the medians of the observed demand distributions without deviating to a statistically significant level. In conjunction with the analysis of means, this correspondence of predicted values to observed values provides further evidence that the forecasting models, with bath demand as the exception, can accurately forecast the distributions of residential end-use demands for a set of households. 


\section{Model application: appliance retrofit program simulation}

The most valuable application of the residential water end-use demand forecasting models developed in this study is for the estimation of water savings attributed to a range of water appliance retrofit programs (e.g., retrofitting toilets from low to high efficiency). Toilet demand, shower demand and clothes washer demand retrofit programs have been selected to exemplify the application of the residential water end use demand forecasting models. To aid in the retrofit program simulations, an interactive residential water end use demand forecasting tool was developed populated by the forecasting models. The 205 household samples from the SEQREUS were used for the appliance retrofit program simulations discussed below.

\subsection{Retrofit programs and results}

Table 8 displays the distribution of the sample based on their clustered star ratings and the associated demand values for the toilet, shower and clothes washer end use categories. Also, the overall average mean household demand for these end use categories is provided. Three retrofit programs were simulated using the developed ANN-based water end use demand forecasting model, namely:

- Toilet retrofit program simulating the installation of 3 star-rated toilets in residential premises that have toilet star ratings of $<2$;

- Shower head retrofit program simulating a retrofit of showerheads of $<2$ star rating shower head with those having $\geq 2$ star rating; and

- Clothes washer retrofit program simulating the installation of 4 star front loading clothes washers to replace those having $<4$ star rating and not being front loading. 


\section{[INSERT TABLE 8]}

The program is assumed to have a 100\% penetration rate. Table 9 details the baseline mean household demand for each of the retrofitted end use appliances, the projected post-retrofit water demand pertaining to each end use, and the mean household savings. The toilet retrofit program had the highest mean daily household saving of $20.54 \mathrm{~L} / \mathrm{hh} / \mathrm{d}$ (i.e. $7.55 \mathrm{~kL} / \mathrm{hh} / \mathrm{y})$. Conversely, the shower retrofit program had the lowest mean daily household saving of $4.54 \mathrm{~L} / \mathrm{hh} / \mathrm{d}(1.66 \mathrm{~kL} / \mathrm{hh} / \mathrm{y})$. A respectable $13.56 \mathrm{~L} / \mathrm{hh} / \mathrm{d}(4.95 \mathrm{~kL} / \mathrm{hh} / \mathrm{y})$ saving was predicted for retrofitting clothes washers. Showering is a behaviourally influenced water use activity while toilets and clothes washers are mechanised appliances. Potentially, the lower shower end use saving may be due to households having efficient shower heads compensating lower flow rates by longer showers.

[INSERT TABLE 9]

\subsection{Model implications for citywide water appliance retrofit program estimation}

The toilet, shower and clothes washer residential water demand end-use forecasting models have demonstrated their intended usefulness at predicting the expected change in demand for various water use appliance retrofit programs. Combining the most effective programs from the toilet, shower and clothes washer program categories, a predicted $14.14 \mathrm{~kL} / \mathrm{hh} / \mathrm{y}$ or a $12.7 \%$ mean reduction in household demand is expected to be achieved. The Gold Coast City Council (GCCC) region in Queensland, Australia where this study was conducted has 206,000 households (GCCC, 2011). If the combination of the most effective programs were instituted over the GCCC municipality and assuming that $50 \%$ of households partake, the expected reduction in demand 
would be 1.45 GL/year, which equates to 582 Olympic sized swimming pools.

\section{Conclusion}

The identification of key determinants of residential end use water demand showed that household income, number of adults, number of children, number of teenagers, and appliance stock efficiency regarding toilet, shower and clothes washer end uses were the predominant determinants. The identification of key determinant results mirrored previous studies such as Kenny (2008), Heinrich (2009), Beal et al. (2010, 2011a \& 2011b), Gatto et al. (2011) and Makki et al. (2011).

The results of applied ANN algorithms demonstrated that the HLSALOA produced the highest level of accuracy. The HLSALOA produced residential end use demand forecasting models with $R^{2}$ ranging from 0.21 for the bath demand forecasting model to 0.60 for the shower demand forecasting model. The clothes washer demand, dishwasher demand and total internal demand account for nearly half or more of the observed variance. The root mean standard errors (RMSEs) of the models were less than half in all cases apart from dishwasher and bath demand forecasting models. The models applied to the validation set produced similar results. The HLSALOA was able to predict the means and medians of the observed demand frequency distributions except in the case of the bath demand forecasting models.

The study demonstrated that applying ANN-based modelling methodology is a feasible means of producing residential water demand end use forecasting models. The most accurate ANN algorithm employed produced models that have a moderate forecast accuracy applying to all end uses with the exception of bath demand. The applicability of the produced residential water demand end-use forecasting models was displayed by their ability to reproduce the demand frequency distributions of the training and validation sets with bath demand being the exception. In turn, the residential water demand end uses forecasting models could be used to simulate water demand reduction retrofit programs. Improvements can be made on this study by testing more complex ANN 
algorithms, identifying determinants of greater applicability and using empirical data with less noise to construct the models.

\section{References}

AS/NZS 6400:2005, Water efficient products - Rating and labelling, Australia/New Zealand Standard

Arbues, F., Garcia-Valinas, M., \& Martinez-Espineira, R. (2003), Estimation of residential water demand: a state of the art review, Journal of Socio-Economics, 32(1), 81-102

Beal, C., Stewart, R.A. \& Huang, T. (2010), South East Queensland residential end use study: Baseline results winter 2010, Urban Water Security Research Alliance Technical Report, (31), 1-45

Beal, C., Stewart, R., Huang, T., \& Rey E., (2011a), Applying smart metering technology to disaggregate residential water end uses in South-East Queensland, Water: Journal of the Australian Water Association, 38(1), 80-84

Beal, C., Stewart, R.A. \& Fielding, K. (2011b), A novel mixed method smart metering approach to reconciling differences between perceived and actual residential end use water consumption, Journal of Cleaner Production, doi:10.1016/j.jclepro.2011.09.007

Beal, C., \& Stewart, R., (2011c), South East Queensland Residential End Use Study: Final Report, Urban Water Security Research Alliance, Technical Report \#47.

Blokker, E., Vreeburg, J. \& Dijk, J. (2010), Simulating residential water demand with a stochastic end-use model, Journal of Water Resources Planning and Management, 136(19), 19-26.

Froukh, M. (2001), Decision-support for domestic water demand forecasting and management, 
Water Resources Management, 15, 363-382.

Gato, S., 2006, Forecasting urban residential water demand, Unpublished PhD thesis, RMIT University.

Gato, S., Jayasuriya, N., \& Roberts, P. (2011), Understanding urban residential end uses of water, Water Science and Technology, 64(1), 36-42

Hsiao, C., Mountain, D., \& Illman, K. (1995), A beyesian integration of end-use metering and conditional-demand analysis, Journal of Business \& Economic Statistics, 13(3), 315-326.

Heinrich, M. (2009), Auckland water use study - Monitoring of water end uses, SB10 New Zealand, (51), Retrieved March 22, 2011, from www.cmsl.co.nz/assets/sm/5916/61/10.PN051Roberti.pdf Jacobs, HE., \& Haarhoff, J. (2004), Application of a residential end-use model for estimating cold and hot water demand, wastewater flow and salinity, Water Research Commission, 30(3), 305-316.

Jorgensen, B., Graymore, M., \& O’Toole, K. (2009), Household water use behaviour: an integrated model, Journal of Environmental Management, 91, 227-236.

Karayiannis, N. \& Venetsanopoulos, A. (1993), Artificial Neural Networks, Boston: Kluwer Academic Publishers.

Kenney, D., Goemans, C., Klein, R., Lowrey, J., \& Reidy, K. (2008), Residential water demand management: Lessons from aurora, Colorado, Journal of the American Water Resources Association, 44(1), 192-207.

Lee, D., Park, No., \& Jeong W. (2012), End-use analysis of household water by metering: the case study in Korea, Water and Environment Journal, DOI: 10.1111/j.1747-6593.2011.00304.x

Loh, M., \& Coghlan, P. (2003), Domestic Water Use Study, Water Corporation, Retrieved March 3, 
2011, from

www.watercorporation.com.au/_files/publicationsregister/12/Domestic_water_use_study.pdf

Makki, A., Stewart, R.A., Panuwatwanich, K., \& Beal, C. (2011), Revealing the determinants of shower water end use consumption: Enabling better targeted urban water conservation strategies, Journal of Cleaner Production, doi:10.1016/j.jclepro.2011.08.007

Mayer, P., De Oreo, W., Opitz, E., Kiefer, J., Davis, W., Dziegielewski, B., \& Nelson, J. (1999), Residential End Uses of Water, USA: AWWA Foundation Research.

Neter, J., Wasserman, W., \& Kutner, M. (1983), Applied linear regression models, Homewood: Richard D. Irwin INC.

Polebitski, A., \& Palmer R. (2010), Seasonal residential water demand forecasting for census tracts, Journal of Water Resources Planning and Management, 136(1), 27-36

Queensland Water Commission (2009), The 2008 water report, Retrieved March 21, 2011, from www.qwc.qld.gov.au/business/pdf/water-report-july-2009.pdf

Willis, R., Stewart, R., Panuwatwanich, K., Capati, B., \& Giurco, D. (2009), Gold Coast domestic water end use study, Water, 36(6), 79-85

Willis, R., Stewart, R.A., Panuwatwanich, K., Jones, S., \& Kyriakides, A. (2010), Alarming visual display monitors affecting shower end use water and energy conservation in Australia residential households, Journal of Resources, Conservation and Recycling, 54(12), 1117-1127.

Willis, R., Stewart, R.A., Panuwatwanich, K., Williams, P., \& Hollingsworth, A. (2011), Quantifying the influence of environmental and water conservation attitudes on household end use water consumption, Journal of Environmental Management, 92(8), 1996-2009. 


\section{Tables}

Table 1: Evaluated predictor variable descriptions

\begin{tabular}{lllllc}
\hline Category & Income category (\$) & Education category & Age category & Region & Occupancy \\
\hline 1 & $<30000$ & Primary School & $15-24$ & Gold Coast & 1 \\
2 & $30000-59999$ & High School & $25-54$ & Brisbane & 2 \\
3 & $60000-89999$ & Trade/TAFE/Tertiary & $55-64$ & Ipswich & 3 \\
4 & $90000-119999$ & Undergraduate & $>64$ & Sunshine Coast & 4 \\
5 & $>120000$ & Postgraduate & - & & - \\
6 & - & - & - & - & 6 \\
\hline
\end{tabular}

Table 2: WELS summary

\begin{tabular}{|c|c|c|c|c|c|c|}
\hline Star Rating & $\begin{array}{r}\text { Tap } \\
(\mathrm{L} / \mathrm{min})\end{array}$ & $\begin{array}{l}\text { Shower } \\
\text { (L/min) }\end{array}$ & Clothes washer & Dishwasher & $\begin{array}{r}\text { Toilet } \\
\text { Half }\end{array}$ & Full \\
\hline 0 & $>16$ & $>16$ & \multirow{7}{*}{$\begin{array}{l}\text { Star rating of clothes } \\
\text { washer is calculated } \\
\text { according to the } \\
\text { outline in section } 2.3 .5 \\
\text { of the AS/NZS } \\
6400: 2005 \text {. }\end{array}$} & \multirow{7}{*}{$\begin{array}{l}\text { Star rating of } \\
\text { dishwasher is } \\
\text { calculated } \\
\text { according to the } \\
\text { outline in } \\
\text { section } 2.3 .5 \text { of } \\
\text { the AS/NZS } \\
6400: 2005 \text {. }\end{array}$} & - & - \\
\hline 1 & $12-16$ & $12-16$ & & & $<4.5$ & $<9.5$ \\
\hline 2 & $9-12$ & $9-12$ & & & $<4.5$ & $<9.5$ \\
\hline 3 & $7.5-9$ & $7.5-9$ & & & $<3.5$ & $<6.5$ \\
\hline 4 & $6-7.5$ & $6-7.5$ & & & $<3.2$ & $<4.7$ \\
\hline 5 & $4.5-6$ & $4.5-6$ & & & - & $<4.7$ \\
\hline 6 & $<4.5$ & - & & & - & $<4.7$ \\
\hline
\end{tabular}


Table 3: Identification of significant determinants

\begin{tabular}{|c|c|c|c|c|c|c|c|c|c|c|c|}
\hline \multirow{2}{*}{$\begin{array}{l}\text { Independent } \\
\text { variable }\end{array}$} & \multicolumn{6}{|c|}{ Ordinal category distribution mean (L/hh/d) } & \multicolumn{3}{|c|}{ ANOVA } & \multicolumn{2}{|c|}{ Regression } \\
\hline & $\mathbf{0}$ & 1 & 2 & 3 & 4 & 5 & Test & df & $p$-value & Gradient & $R^{2}$ \\
\hline \multicolumn{12}{|c|}{ Total internal demand } \\
\hline Region & & 352.26 & 338.19 & 286.22 & 333.86 & & KW & 3 & 0.50 & & \\
\hline Income & & 247.21 & 330.05 & 375.50 & 443.78 & 343.69 & KW & 4 & 0.00 & & \\
\hline Education & & 344.75 & 303.95 & 330.09 & 338.92 & 373.00 & KW & 4 & 0.28 & & \\
\hline No. of Adults & & 241.74 & 342.45 & 406.23 & 493.13 & & KW & 3 & 0.00 & 68.87 & 0.10 \\
\hline No. of Children & & 421.72 & 390.35 & 478.73 & & & KW & 2 & 0.43 & 61.21 & 0.07 \\
\hline No. of Children* & 303.23 & 421.59 & & & & & MW & - & 0 & & \\
\hline No. of Teenagers & & 454.1 & 543.9 & & & & MW & - & 0.24 & 150.57 & 0.18 \\
\hline No. of Teenagers* & 306.73 & 506.74 & & & & & MW & - & 0 & & \\
\hline
\end{tabular}

\begin{tabular}{|c|c|c|c|c|c|c|c|c|c|c|c|}
\hline \multicolumn{12}{|c|}{ Toilet demand } \\
\hline Region & & 47.54 & 50.54 & 50.09 & 59.77 & & KW & 3 & 0.03 & & \\
\hline Income & & 49.72 & 53.99 & 51.21 & 64.36 & 55.75 & KW & 4 & 0.14 & & \\
\hline Education & & & 47.65 & 52.73 & 44.36 & 55.71 & KW & 3 & 0.59 & & \\
\hline No. of Adults & & 0.00 & 0.00 & 0.00 & 0.00 & & KW & 4 & 0.00 & 11.51 & 0.10 \\
\hline No. of Children & & 45.96 & 56.8 & 66.04 & & & KW & 2 & 0.652 & 4.23 & 0.01 \\
\hline No. of Children* & 52.66 & 55.43 & & & & & MW & - & 0.38 & & \\
\hline No. of Teenagers & & 59.06 & 59.06 & & & & MW & - & 0.203 & 22.41 & 0.05 \\
\hline No. of Teenagers* & 51.57 & 65.51 & & & & & MW & - & 0.04 & & \\
\hline Star Rating & 69.02 & 55.25 & 47.69 & 39.87 & & & KW & 5 & 0.01 & -9.39 & 0.11 \\
\hline \multicolumn{12}{|c|}{ Tap demand } \\
\hline Region & & 87.86 & 54.17 & 55.08 & 49.85 & & KW & 3 & 0.00 & & \\
\hline Income & & 50.91 & 60.32 & 56.15 & 73.85 & 57.12 & KW & 4 & 0.14 & & \\
\hline Education & & & 57.93 & 55.47 & 59.33 & 61.84 & KW & 3 & 0.59 & & \\
\hline No. of Adults & & 39.38 & 65.05 & 71.22 & 104.24 & & KW & 3 & 0.00 & 13.00 & 0.07 \\
\hline No. of Children & & 60.76 & 56.87 & 60.76 & & & KW & 2 & 0.652 & 4.23 & 0.01 \\
\hline No. of Children* & 59.7 & 65.15 & & & & & MW & - & 0.22 & & \\
\hline No. of Teenagers & & 87.24 & 54.86 & & & & MW & - & 0.203 & 38.96 & 0.17 \\
\hline No. of Teenagers* & 59.7 & 65.15 & & & & & MW & - & 0.03 & & \\
\hline Star Rating & 57.41 & 79.01 & 25.91 & 27.18 & 25.43 & 21.86 & KW & 4 & 0.34 & -0.17 & 0.00 \\
\hline \multicolumn{12}{|c|}{ Shower demand } \\
\hline Region & & 93.50 & 94.80 & 103.90 & 106.20 & & KW & 3 & 0.93 & & \\
\hline Income & & 62.54 & 97.50 & 122.98 & 118.10 & 116.27 & KW & 4 & 0.00 & & \\
\hline Education & & & 88.24 & 91.51 & 95.57 & 90.28 & KW & 3 & 0.65 & & \\
\hline No. of Adults & & 73.21 & 104.15 & 129.11 & 126.43 & & KW & 3 & 0.00 & 16.20 & 0.03 \\
\hline No. of Children & & 99.42 & 123.2 & 179.4 & & & KW & 2 & 0.01 & 22.01 & 0.04 \\
\hline No. of Teenagers & & 147.9 & 166.1 & & & & MW & - & 0.06 & 53.32 & 0.11 \\
\hline Star Rating & 140.16 & 111.12 & 86.59 & 89.94 & 104.04 & 115.66 & KW & - & 0.59 & -5.90 & 0.02 \\
\hline Star Rating* & & 124.92 & 86.21 & & & & MW & - & 0.04 & & \\
\hline
\end{tabular}




\begin{tabular}{|c|c|c|c|c|c|c|c|c|c|c|c|}
\hline \multicolumn{12}{|c|}{ Dishwasher demand } \\
\hline Region & & 5.24 & 6.18 & 4.55 & 5.31 & & KW & 3 & 0.79 & & \\
\hline Income & & 3.69 & 4.74 & 7.58 & 8.61 & 6.71 & KW & 4 & 0.03 & & \\
\hline Education & & 2.30 & 5.51 & 4.41 & 7.03 & 8.25 & KW & 3 & 0.04 & & \\
\hline No. of Adults & & 9.25 & 9.59 & 12.66 & 16.90 & & KW & 3 & 0.40 & 2.06 & 0.04 \\
\hline No. of Children & & 7.62 & 9.31 & 9.80 & & & KW & 2 & 0.66 & 2.65 & 0.07 \\
\hline No. of Children* & 4.49 & 8.89 & & & & & MW & - & 0 & & \\
\hline No. of Teenagers & & 5.63 & 6.33 & & & & MW & - & 0.81 & 1.29 & 0.01 \\
\hline No. of Teenagers* & 5.78 & 6.69 & & & & & MW & - & 0.09 & & \\
\hline Has Dishwasher & 0.00 & 9.23 & & & & & MW & - & 0.00 & & \\
\hline \multicolumn{12}{|c|}{ Clothes washer demand } \\
\hline Region & & 63.23 & 89.65 & 57.96 & 60.81 & & KW & 3 & 0.01 & & \\
\hline Income & & 40.84 & 66.64 & 97.64 & 102.73 & 70.50 & KW & 4 & 0.00 & & \\
\hline Education & & 62.86 & 64.98 & 74.06 & 83.84 & 68.61 & KW & 3 & 0.26 & & \\
\hline No. of Adults & & 46.42 & 80.12 & 84.20 & 120.70 & & KW & 3 & 0.00 & 14.14 & 0.04 \\
\hline No. of Children & & 104.68 & 97.47 & 109.60 & & & KW & 2 & 0.92 & 23.86 & 0.10 \\
\hline No. of Children* & 61.31 & 105.9 & & & & & MW & - & 0 & & \\
\hline No. of Teenagers & & 87.88 & 112.69 & & & & MW & - & 0.98 & 22.38 & 0.08 \\
\hline No. of Teenagers* & 67.52 & 104.33 & & & & & MW & - & 0.01 & & \\
\hline Loading (front/top) & & 50.74 & 79.21 & & & & MW & - & 0.00 & & \\
\hline Rating & & 118.14 & 81.18 & 84.36 & 64.37 & & KW & 2 & 0.11 & & \\
\hline \multicolumn{12}{|c|}{ Bath demand } \\
\hline Region & & 7.76 & 5.75 & 0.23 & 3.84 & & KW & 3 & 0.02 & & \\
\hline Income & & 2.43 & 2.91 & 6.15 & 9.27 & 7.44 & KW & 4 & 0.04 & & \\
\hline Education & & & 2.20 & 5.51 & 7.67 & 4.55 & KW & 3 & 0.03 & & \\
\hline No. of Adults & & 5.20 & 27.61 & 31.82 & 7.20 & & KW & 3 & 0.09 & 0.90 & 0.00 \\
\hline No. of Children & & 9.38 & 6.54 & 3.61 & & & KW & 2 & 0.603 & 4.21 & 0.06 \\
\hline No. of Children* & 2.78 & 10.86 & & & & & MW & - & 0 & & \\
\hline No. of Teenagers & & 4.41 & 7.77 & & & & MW & - & 0.963 & 0.48 & 0.00 \\
\hline No. of Teenagers* & 4.66 & 5.38 & & & & & MW & - & 0.97 & & \\
\hline
\end{tabular}

* Represents a re-clustering of demographic or appliance variables to identify relationships between the variable the respected water demand end use to identify key determinants. 
Table 4: Residential water demand end use forecasting model input variables

\begin{tabular}{lllllll}
\hline $\begin{array}{l}\text { Total internal } \\
\text { demand }\end{array}$ & Toilet & Tap & Shower & $\begin{array}{l}\text { Clothes } \\
\text { washer }\end{array}$ & Dishwasher & Bath \\
\hline Income & Income & Income & Income & Income & Income & Income \\
No. of adults & No. of adults & No. of adults & No. of adults & No. of adults & No. of adults & Education \\
No. of children & $\begin{array}{l}\text { No. of } \\
\text { children }\end{array}$ & No. of children & No. of children & No. of children & No. of children & No. of children \\
No. of & $\begin{array}{l}\text { No. of } \\
\text { teenagers }\end{array}$ & $\begin{array}{l}\text { No. of } \\
\text { teenagers }\end{array}$ & $\begin{array}{l}\text { No. of } \\
\text { teenagers }\end{array}$ & $\begin{array}{l}\text { No. of } \\
\text { teenagers }\end{array}$ & $\begin{array}{l}\text { No. of } \\
\text { teenagers }\end{array}$ & \\
$\begin{array}{l}\text { Toilet star } \\
\text { rating }\end{array}$ & $\begin{array}{l}\text { Toilet star } \\
\text { rating }\end{array}$ & & Shower star & $\begin{array}{l}\text { Clothes washer } \\
\text { loading }\end{array}$ & $\begin{array}{l}\text { Dishwasher } \\
\text { installed }\end{array}$ & \\
$\begin{array}{l}\text { Shower star } \\
\text { rating } 1\end{array}$ & & & $\begin{array}{l}\text { rating } 1 \\
\text { Shower star }\end{array}$ & $\begin{array}{l}\text { Clothes washer } \\
\text { star rating }\end{array}$ & & \\
$\begin{array}{l}\text { Shower star } \\
\text { rating } \geq 2\end{array}$ & & & & & & \\
$\begin{array}{l}\text { Clothes washer } \\
\text { loading }\end{array}$ & & & & & & \\
$\begin{array}{l}\text { Clothes washer } \\
\text { star rating }\end{array}$ & & & & & & \\
\hline
\end{tabular}


Table 5: Applied artificial neural networks

\begin{tabular}{|c|c|c|c|c|c|c|}
\hline ANN applied & End use & ARE & $\operatorname{AAE}(\mathrm{L} / \mathbf{h h} / \mathbf{d})$ & RMSE (L/hh/d) & MW p-value & $R^{2}$ \\
\hline \multirow[t]{7}{*}{ HLSA } & Toilet & 0.35 & 14.89 & 17.03 & 0.32 & 0.33 \\
\hline & Tap & 0.62 & 20.36 & 26.25 & 0.10 & 0.28 \\
\hline & Shower & 0.83 & 35.64 & 49.92 & 0.27 & 0.51 \\
\hline & Clothes Washer & - & 24.19 & 31.77 & 0.17 & 0.5 \\
\hline & Dishwasher & - & 2.95 & 4.48 & 0.59 & 0.56 \\
\hline & Bath & - & 5.87 & 11.52 & 0.00 & 0.25 \\
\hline & Total Internal & 0.34 & 79.59 & 102.36 & 0.29 & 0.28 \\
\hline \multirow[t]{7}{*}{ HLSALOA } & Toilet & 0.36 & 14.19 & 18.03 & 0.24 & 0.33 \\
\hline & Tap & 0.52 & 18.53 & 24.47 & 0.3 & 0.37 \\
\hline & Shower & 0.81 & 32.44 & 45.25 & 0.17 & 0.6 \\
\hline & Clothes Washer & - & 25.81 & 32.86 & 0.17 & 0.57 \\
\hline & Dishwasher & - & 2.91 & 4.43 & 0.48 & 0.57 \\
\hline & Bath & - & 6.03 & 11.80 & 0 & 0.21 \\
\hline & Total Internal & 0.30 & 69.48 & 87.77 & 0.47 & 0.47 \\
\hline \multirow[t]{7}{*}{ RBFN } & Toilet & 0.34 & 13.73 & 17.70 & 0.34 & 0.36 \\
\hline & Tap & 0.63 & 20.30 & 26.21 & 0.20 & 0.28 \\
\hline & Shower & 0.90 & 38.56 & 54.60 & 0.13 & 0.42 \\
\hline & Clothes Washer & - & 27.53 & 36.54 & 0.08 & 0.47 \\
\hline & Dishwasher & - & 3.31 & 5.04 & 0.17 & 0.45 \\
\hline & Bath & - & 5.96 & 11.81 & 0.00 & 0.21 \\
\hline & Total Internal & 0.31 & 70.37 & 91.32 & 0.38 & 0.43 \\
\hline
\end{tabular}


Table 6: Training set analysis statistics

\begin{tabular}{lrrrrrr}
\hline End use & $\begin{array}{r}\text { Mean of } \\
\text { Observed }\end{array}$ & ARE & $\begin{array}{r}\text { AAE } \\
\text { (L/hh/d) }\end{array}$ & $\begin{array}{r}\text { RMSE } \\
\text { (L/hh/d) }\end{array}$ & $\begin{array}{r}\text { RMSE of mean } \\
\text { \%o }\end{array}$ & $\boldsymbol{R}^{2}$ \\
\hline Toilet & 49.69 & 0.36 & 14.19 & 18.03 & 36 & 0.33 \\
Tap & 56.64 & 0.52 & 18.53 & 24.47 & 43 & 0.37 \\
Shower & 92.24 & 0.81 & 32.44 & 45.25 & 49 & 0.6 \\
Clothes Washer & 66.53 & - & 25.81 & 32.86 & 49 & 0.57 \\
Dishwasher & 5.40 & - & 2.91 & 4.43 & 82 & 0.57 \\
Bath & 3.96 & -6.03 & 11.80 & 297 & 0.21 \\
Total Internal & 284.89 & 0.30 & 69.48 & 87.77 & 30 & 0.47 \\
\hline
\end{tabular}

Table 7: Validation set analysis statistics

\begin{tabular}{|c|c|c|c|c|c|c|}
\hline End Use & $\begin{array}{l}\text { Mean of } \\
\text { Observed }\end{array}$ & ARE & $\begin{array}{r}\text { AAE } \\
(\mathrm{L} / \mathrm{hh} / \mathbf{d})\end{array}$ & $\begin{array}{r}\text { RMSE } \\
\text { (L/hh/d) }\end{array}$ & $\begin{array}{r}\text { RMSE } \\
\text { \% of Mean }\end{array}$ & $R^{2}$ \\
\hline Toilet & 51.26 & 0.37 & 13.82 & 18.57 & 36 & 0.51 \\
\hline Tap & 55.13 & 0.36 & 13.96 & 18.83 & 34 & 0.69 \\
\hline Shower & 91.97 & 0.82 & 24.36 & 31.17 & 33 & 0.75 \\
\hline Clothes Washer & 65.96 & 0.35 & 19.61 & 26.26 & 29 & 0.56 \\
\hline Dishwasher & 4.46 & - & 2.08 & 3.21 & 71 & 0.66 \\
\hline Bath & 2.84 & - & 4.93 & 8.85 & 311 & 0.23 \\
\hline Total Internal & 282.98 & 0.31 & 62.34 & 80.01 & 28 & 0.47 \\
\hline
\end{tabular}


Table 8: Retrofit program water end uses demand distribution

\begin{tabular}{|c|c|c|c|c|c|c|}
\hline \multirow{2}{*}{$\begin{array}{l}\text { Category } \\
\text { Toilet end use }\end{array}$} & \multicolumn{6}{|c|}{ WELS star rating } \\
\hline & $\mathbf{0}$ & 1 & 2 & 3 & 4 & Overall \\
\hline Number of samples & 52 & 68 & 56 & 29 & & 205 \\
\hline Percent of sample set (\%) & 25.37 & 33.17 & 27.32 & 14.15 & & 100.00 \\
\hline Mean household demand (L/hh/d) & 88.84 & 60.29 & 45.17 & 38.96 & & 60.39 \\
\hline Shower & $<2^{\dagger}$ & & $\geq 2^{\dagger}$ & & & Overall \\
\hline Number of samples & 40 & & 165 & & & 205 \\
\hline Percentage of sample set (\%) & 19.55 & & 80.45 & & & 100.00 \\
\hline Mean household demand (L/hh/d) & 104.25 & & 86.61 & & & 90.05 \\
\hline Clothes washer & $\mathbf{0}$ & 1 & 2 & 3 & 4 & Overall \\
\hline Number of samples & 20 & 5 & 19 & 58 & 103 & 205 \\
\hline Percentage of sample set (\%) & 9.76 & 2.44 & 9.27 & 28.29 & 50.24 & 100.00 \\
\hline Mean household demand (L/hh/d) & 58.51 & 108.02 & 77.36 & 69.82 & 52.71 & 61.76 \\
\hline
\end{tabular}

Table 9: ANN model predicted savings from retrofit programs

\begin{tabular}{|c|c|c|c|c|}
\hline \multirow[b]{2}{*}{ Retrofit program } & \multirow{2}{*}{$\begin{array}{r}\text { Baseline demand } \\
(\mathrm{L} / \mathrm{hh} / \mathrm{d})\end{array}$} & \multirow{2}{*}{$\begin{array}{r}\text { Post retrofit demand } \\
(\mathrm{L} / \mathrm{hh} / \mathrm{d})\end{array}$} & \multicolumn{2}{|c|}{ Mean saving predicted } \\
\hline & & & $(\mathrm{L} / \mathrm{hh} / \mathrm{d})$ & $(\mathbf{k L} / \mathbf{h h} / \mathbf{y})$ \\
\hline Toilet & 60.39 & 39.85 & 20.54 & 7.50 \\
\hline Shower & 90.05 & 85.51 & 4.54 & 1.66 \\
\hline Clothes washer & 61.76 & 48.20 & 13.56 & 4.95 \\
\hline
\end{tabular}


Figure captions:

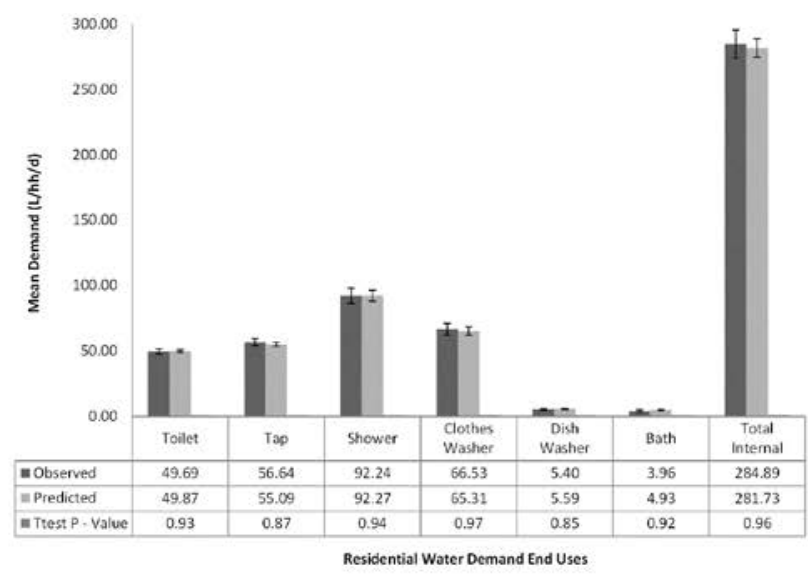

A) Training Mean of Prediction Vs. Observed

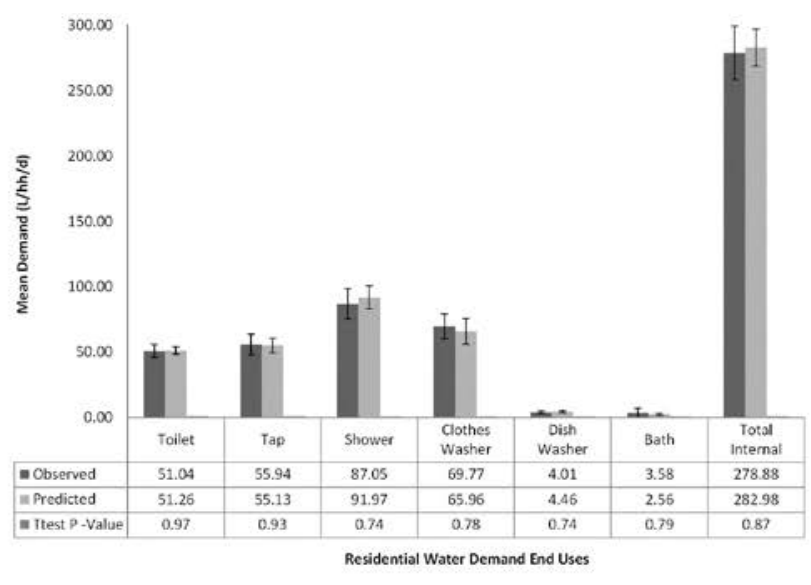

B) Validation Mean Prediction Vs. Observed

Figure 1: Analysis of training and validation predicted demand distributions vs. observed demand distributions 